\title{
PEMBERDAYAAN PELAKU USAHA KULINER DI KANTIN UNIVERSITAS SAHID JAKARTA MELALUI SISTEM PEMASARAN ONLINE
}

\author{
Intan Nurul Azni', Giyatmi², Julfi Restu Amelia ${ }^{3}$ \\ Fakultas Teknologi Pangan dan Kesehatan, Universitas sahid Jakarta \\ Jl. Soepomo No, 84 Tebet, Jakarta Selatan \\ Email Korespondensi: intanurulazni@gmail.com
}

\begin{abstract}
ABSTRAK
Tujuan kegiatan ini adalah untuk meningkatkan kapasitas usaha kuliner kantin Universitas Sahid Jakarta melalui sistem pemasaran online. Mitra merupakan para pelaku usaha kuliner di kantin Universitas Sahid Jakarta. Masalah yang dihadapi oleh mitra adalah masih rendahnya kapasitas usaha terhadap produk dijual. Hal yang menjadi penyebab adalah sistem pemasaran produk yang masih bersifat konvensional. Masalah lain yang dihadapi oleh mitra adalah mengenai sanitasi dan higienitas dari produk makanan yang belum memperhatikan aspek sanitasi lingkungan serta higiene personal. Selain itu, pemilihan kemasan untuk makanan yang dibawa pulang juga masih kurang tepat, kurang menarik, dan menyimpang dari aspek keamanan pangan. Solusi yang ditawarkan oleh pengusul kegiatan ini berupa pelatihan higiene dan sanitasi usaha jasa boga, pendampingan dalam memilih kemasan dan label untuk penjualan online, pendampingan promosi produk secara online, dan pendampingan dalam mendaftarkan produk dalam aplikasi online. Solusi yang ditawarkan diharapkan mampu meningkatkan kapasitas usaha jasa boga, sehingga dapat meningkatkan omset dari mitra. Saat ini menu yang dijual di Kantin Universitas Sahid Jakarta telah terdaftar di GrabFood, dengan akun bernama KANISA Kafetaria. Selain itu KANISA Kafetaria juga telah memiliki akun media sosial Instagram sehingga memudahkan untuk melalukan promosi secara online. Kendala yang dihadapi saat ini adalah hasil penjualan belum meningkat secara signifikan sehingga untuk tahap berikutnya masih dibutuhkan pendampingan untuk promosi produk.
\end{abstract}

Kata kunci: Kantin, pemasaran, promosi, online

\begin{abstract}
The purpose of this activity was to increase the capacity of the Sahid Jakarta University's culinary entrepreneurs through an online marketing system. The partners of this activity were culinary entrepreneurs in the Sahid University Jakarta canteen. The problem faced by partners was low business capacity of the sold products. One of the reason of this problem was the conventional method of product marketing system. Another problem faced by partners was regarding sanitation and hygiene of food products that do not pay attention to environmental sanitation and personal hygiene aspects. In addition, the selection of packaging for taken away food was also still inappropriate, less attractive, and deviates from food safety aspect. The solutions offered from joining this activity include hygiene and sanitation training, assistance in selecting packaging and labels for online sales, assistance in online promotion system, and products registering assistance in online applications. The solution offered was expected to increase the catering capacity business, so that it can increase partner's revenue. Currently, the menu of Sahid Jakarta University Canteen has been registered at GrabFood, with an account called KANISA Cafeteria. Besides that KANISA Cafeteria also has an Instagram social media account that make it easy for online promotion. The obstacle currently faced is sales results have not increased significantly, so for the next phase the partners still need assistance for product promotion.
\end{abstract}

Keywords: Canteen, marketing, promotion, online 


\section{PENDAHULUAN}

Mitra pada program ini adalah para pelaku usaha jasa boga di kantin Universitas Sahid Jakarta yang beralamat di jalan Prof. Dr. Soepomo, SH No. 84, Tebet Jakarta Selatan. Para pelaku usaha tersebut dinaungi oleh Koperasi Karyawan Universitas Sahid Jakarta.

Kantin Universitas Sahid Jakarta terletak di bagian belakang Universitas Sahid Jakarta dan memiliki luas 6 x $11 \mathrm{~m}$. Kantin Universitas Sahid Jakarta mampu menampung 15 counter untuk pelaku usaha jasa boga. Kantin Universitas Sahid Jakarta beroperasi dari setiap hari Senin-Sabtu dari pukul 07.00-20.00. Para pembeli produk jasa boga di kantin Universitas Sahid saat ini umumnya hanya kalangan sivitas akademika Universitas Sahid Jakarta serta masyarakat sekitar kampus (Gambar 1).

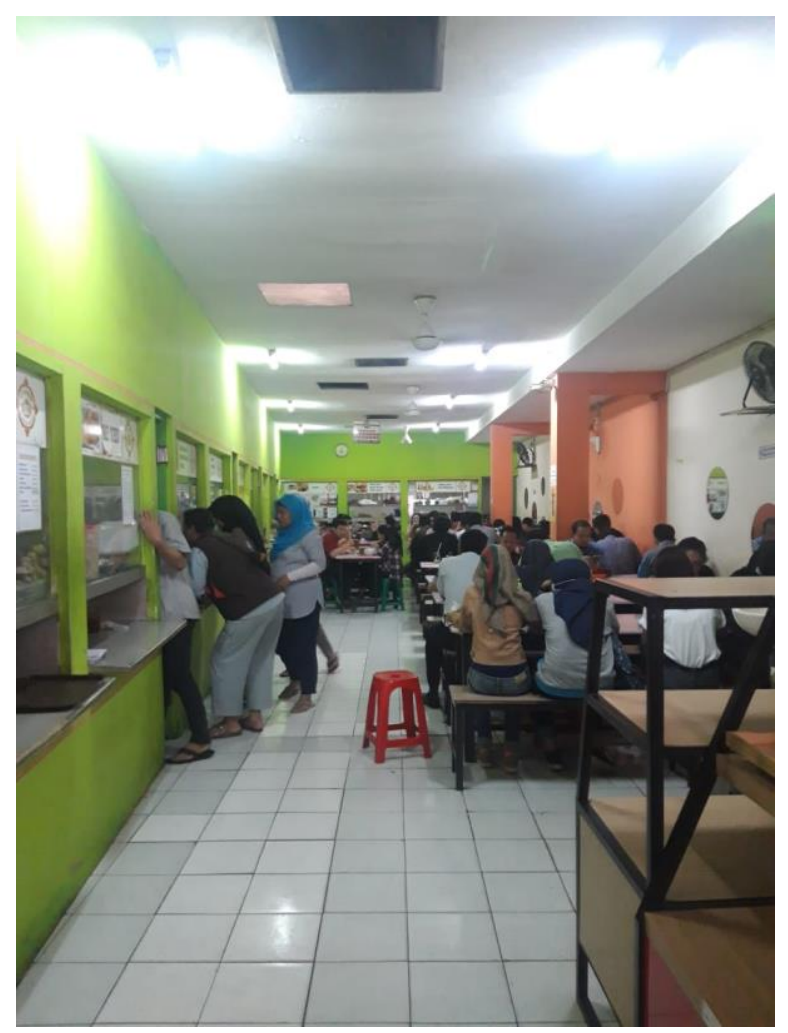

Gambar 1. Kantin Universitas Sahid Jakarta

Biaya sewa counter yang dibayarkan oleh pelaku usaha jasa boga di kantin Usahid terdiri dari 2 harga, yaitu Rp 550.000,-/bulan untuk counter kecil dan Rp 650.000,-/bulan untuk counter reguler. Adapun counter yang termasuk counter kecil adalah counter seblak; nasi tutug oncom; siomay, batagor, dan bakso; dan nasi goreng. Berikut ini adalah daftar pelaku usaha jasa boga di kantin Universitas Sahid Jakarta (Tabel 1).

Tabel 1. Daftar Produk Jasa Boga yang Dijual di Kantin Universitas Sahid Jakarta

\begin{tabular}{|c|l|c|}
\hline No & \multicolumn{1}{|c|}{ Jenis Produk yang Dijual } & Nama Pemilik Usaha \\
\hline 1 & Seblak & Ibu Nunung \\
\hline 2 & Nasi tutug oncom & Ibu Nunung \\
\hline 3 & Siomay, batagor, dan bakso & Bapak Kusno \\
\hline
\end{tabular}




\begin{tabular}{|c|l|c|}
\hline No & Jenis Produk yang Dijual & Nama Pemilik Usaha \\
\hline 4 & Mie ayam & Ibu Anna Bellandina \\
\hline 5 & Nasi Gudeg & Ibu Rohana \\
\hline 6 & Aneka soto & Ibu Nenti \\
\hline 7 & Masakan padang & Bapak Ahmad \\
\hline 8 & Nasi goreng dan mie goreng & Ibu Sri \\
\hline 9 & Nasi bebek & Ibu Novi \\
\hline 10 & Ayam bakar \& gado-gado & Bapak Tri \\
\hline 11 & Nasi rames & Bapak Nanang \\
\hline 12 & Aneka chicken steak & Ibu Ratika \\
\hline 13 & Piscok lumer dan rice bowl & Ibu Yati \\
\hline 14 & Pecel ayam dan lele & Bapak Idris \\
\hline 15 & Aneka jus & \\
\hline
\end{tabular}

Saat ini produk Jasa Boga yang dijual di kantin Universitas Sahid Jakarta masih bersifat konvensional. Pembeli yang umumnya civitas akademika Universitas Sahid Jakarta datang ke kantin lalu memesan makan atau minuman yang dijual, kemudian langsung membayar. Namun ada satu counter yaitu seblak, yang sudah mulai menjelajah sistem pemasaran dengan sistem online yaitu dengan bergabung dengan aplikasi GrabFood.

Permasalahan yang saat ini dihadapi oleh pelaku usaha produk jasa boga di Universitas Sahid Jakarta masih rendahnya kapasitas usaha terhadap produk tersebut. Salah satu yang mungkin menjadi penyebab adalah sistem pemasaran produk yang masih bersifat konvensional. Sehingga konsumennya masih terbatas civitas akademika Universitas Sahid Jakarta. Di zaman modern ini, untuk lebih memperluas pemasaran produk, sebaiknya produsen juga memasarkan produk dengan cara modern, salah satunya dengan metode online. Dengan adanya pemasaran secara online, sebuah badan usaha dapat mempromosikan produknya dalam skala yang lebih luas. 1 Beberapa fitur atau aplikasi seperti instagram dan vendor online dapat menjadi pilihan untuk memasarkan produk.

Masalah lain yang dihadapi oleh mitra adalah mengenai sanitasi dan higienitas dari produk makanan. Berdasarkan observasi, masih ditemukan para penjual produk makanan/minuman yang belum memperhatikan aspek sanitasi lingkungan serta higiene personal. Berdasarkan hasil uji koliform pada salah satu minuman yang dijual di kantin Universitas Sahid, didapatkan jumlah koliform yang sangat tinggi yaitu $1100 \mathrm{MPN} / \mathrm{mL} .2$ Hal ini dapat disebabkan masih rendahnya pengetahuan tentang sanitasi dan higiene pelaku usaha produk jasa boga kantin Universitas Sahid Jakarta. Pengetahuan penjual makanan dan minuman sangat berperan penting dalam mencegah penyakit bawaan makanan (food borne disease).3 Masalah lainnya yang dihadapi oleh pelaku usaha jasa boga di kantin Universitas Sahid adalah masalah pemilihan kemasan untuk makanan yang dibawa pulang. Beberapa counter masih menggunakan sterofoam untuk membungkus makanan yang dibawa pulang oleh pembeli. Hal tersebut menyimpang dari praktek keamanan pangan, di mana zat kimia yang terdapat pada styrofoam dapat bermigrasi ke dalam pangan terutama makanan yang berbahan minyak dan panas. Tujuan dari kegiatan pengabdian masyarakat ini adalah untuk meningkatkan kapasitas usaha jasa boga kantin Universitas Sahid Jakarta, kecamatan Tebet Jakarta Selatan. 


\section{METODE PELAKSANAAN}

Berdasarkan permasalahan yang telah diuraikan sebelumnya dan kesepakatan antara tim pengusul dengan mitra pelaku usaha jasa boga di kantin Universitas Sahid Jakarta, maka metode yang ditawarkan sebagai solusi adalah sebagai berikut:

1. Pemetaan Masalah

Pada tahap ini dilakukan pemetaan masalah yang dihadapi mitra.

2. Pelatihan Higiene dan Sanitasi Usaha Jasa Boga

Pelatihan ini bertujuan untuk meningkatkan pengetahuan pelaku usaha jasa boga di

kantin Universitas Sahid Jakarta tentang pentingnya higiene dan sanitasi produk makanan siap saji agar terjamin kemanan pangannya.

3. Pendampingan dalam Memilih Kemasan dan Label untuk Penjualan Online

Pelatihan ini bertujuan untuk membantu pelaku usaha jasa boga di kantin Universitas Sahid dalam menemukan kemasan dan label yang aman, menarik, dan terjangkau sebagai wadah produk yang akan dijual secara online.

4. Pendampingan Promosi Produk secara Online

Kegiatan ini bertujuan untuk membantu pelaku usaha jasa boga di kantin Universitas Sahid dalam mempromosikan produknya secara online. Kegiatan ini berupa pendampingan dalam promosi dalam aplikasi Instagram dan pendampingan dalam membuat ilustrasi produk untuk dipromosikan secara online, dan pendampingan pembuatan tag line produk yang menarik.

5. Pendampingan dalam Mendaftarkan Produk dalam Aplikasi Online

Kegiatan ini bertujuan untuk membantu pelaku usaha jasa boga di kantin Universitas Sahid dalam mendaftarkan produk yang dijual ke dalam satu akun online.

6. Pelatihan manajemen tata kelola usaha

Kegiatan ini bertujuan untuk meningkatkan kemampuan mitra dalam mengatur tata kelola usaha jasa boga.

7. Keberlanjutan

Program ini bukan merupakan kegiatan yang bersifat instan sehingga keberlanjutan program menjadi komitmen bersama antara pengusul melalui LPPM Universitas Sahid Jakarta dan mitra koperasi karyawan Universitas sahid Jakarta.

\section{HASIL DAN PEMBAHASAN}

Berikut ini adalah realisasi dari beberapa rencana yang disusun dalam melakukan kegiatan pengabdian masyarakat di Kantin Universitas Sahid Jakarta:

1. Pemetaan Masalah

Pada tahap ini dilakukan pemetaan masalah yang dihadapi mitra yaitu Koperasi Karyawan Universitas Sahid Jakarta. Pada tahap ini didapatkan informasi jumlah penjual makanan dan minuman yang tergabung di Kantin Universitas Sahid Jakarta. Selain jumlah penjual, didapatkan pula informasi berupa jenis menu yang disajikan, jam operasional kantin, dan pelanggan kantin Universitas Sahid Jakarta. Selain itu, pengusul kegiatan juga melakukan observasi dan mengumpulkan kuesioner terkait tingkat kepuasan pelanggan Kantin Universitas Sahid Jakarta.

Dari kuesioner yang disebar kepada 50 pelanggan didapatkan informasi bahwa mayoritas pelanggan adalah mahasiswa/i Universitas Sahid Jakarta. Hasil survei 
menunjukkan bahwa sebagian besar pelanggan sudah merasa puas terhadap harga, rasa, dan porsi dari menu yang dijual di Kantin Universitas Sahid Jakarta. Selain itu mereka juga merasa puas dengan kesopanan dan responsifitas penjual, dan keamanan di Kantin Universitas Sahid Jakarta. Namun lebih dari setengah responden tidak puas dengan kehigienitasan, variasi menu, dan tampilan menu. Selain itu pelanggan juga tidak puas dengan keterjangkauan, kenyamanan, fasilitas pendukung seperti wifi, sanitasi, dan kerapihan penjual makanan/minuman di kantin Universitas Sahid Jakarta. $^{4}$

2. Pelatihan Higiene dan Sanitasi Usaha Jasa Boga serta Pendampingan dalam Memilih Kemasan dan Label untuk Penjualan Online

Setelah pengusul kegiatan menyatakan keinginan untuk melakukan kegiatan pengabdian masyarakat di kantin Universitas Sahid Jakarta dan mendapat tangapan yang baik oleh mitra, maka dilakukan kegiatan sosialisasi ke para penjual makanan dan minuman di Universitas Sahid Jakarta. Para pedagang antusias untuk terlibat di kegiatan ini. Selain sosialisasi dilakukan juga pelatihan kecil tentang higienitas dan sanitasi serta keamanan pangan dari segi kemasan, mengingat masih terdapat beberapa penjual yang menggunakan wadah styrofoam untuk mengemas makanan take away. Pelatihan ini bertujuan untuk meningkatkan pengetahuan pelaku usaha jasa boga di kantin Universitas Sahid Jakarta tentang pentingnya higiene dan sanitasi produk makanan siap saji agar terjamin kemanan pangannya. Selain itu pelatihan ini juga untuk membantu pelaku usaha jasa boga di kantin Universitas Sahid dalam menemukan kemasan dan label yang aman, menarik, dan terjangkau sebagai wadah produk yang akan dijual secara online Pada saat sosialisasi diinfokan bahwa harga yang nantinya akan tertera di aplikasi online sudah termasuk dengan kemasan yang aman sehingga harga akan lebih mahal dibandingkan yang mereka jual di tempat. Pengusul kegiatan memberikan contoh kemasan yang dapat digunakan oleh kantin agar seterusnya dapat menggunakan kemasan tersebut (Gambar 2).

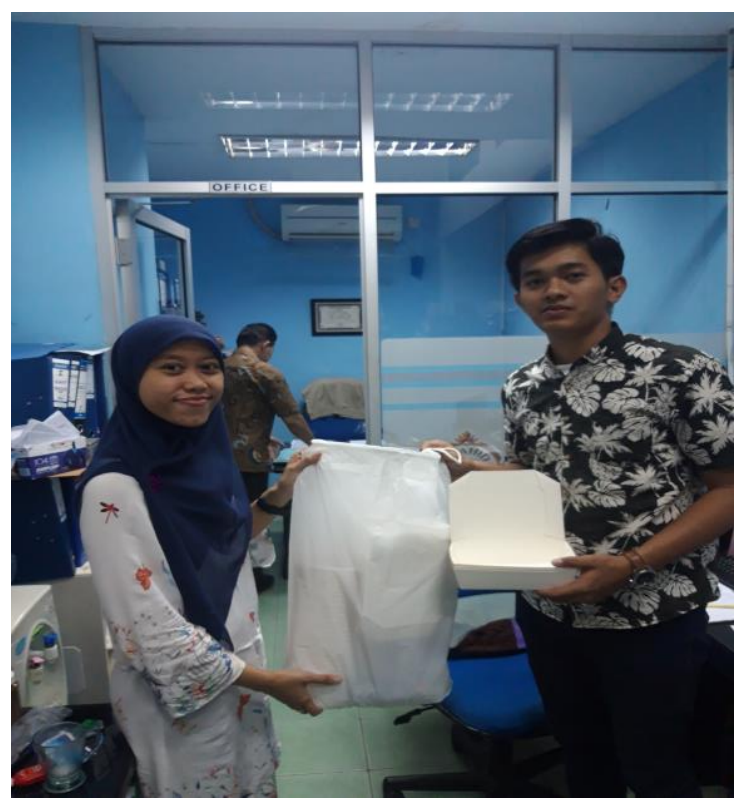

Gambar 2. Penyerahan Sampel Kemasan ke Pihak Koperasi Karyawan Universitas Sahid Jakarta 
3. Pendampingan Promosi Produk secara Online

Kegiatan ini bertujuan untuk membantu pelaku usaha jasa boga di kantin Universitas Sahid dalam mempromosikan produknya secara online. Kegiatan ini berupa pendampingan dalam promosi dalam aplikasi Instagram dan pendampingan dalam membuat ilustrasi produk untuk dipromosikan secara online, dan pendampingan pembuatan tag line produk yang menarik.

Setiap counter makanan/minuman di Kantin Universitas Sahid mendapat sesi foto perwakilan produk, di mana foto produk tersebut akan diunggah di Instagram dan GrabFood untuk lebih menarik perhatian calon pelanggan. Untuk lebih mudah diingat dan dikenali maka nama akun Kantin Universitas Sahid Jakarta yang digunakan di aplikasi adalah KANISA Kafetaria. Saat ini akun instagramnya adalah @kanisa_kafetaria (Gambar 3).

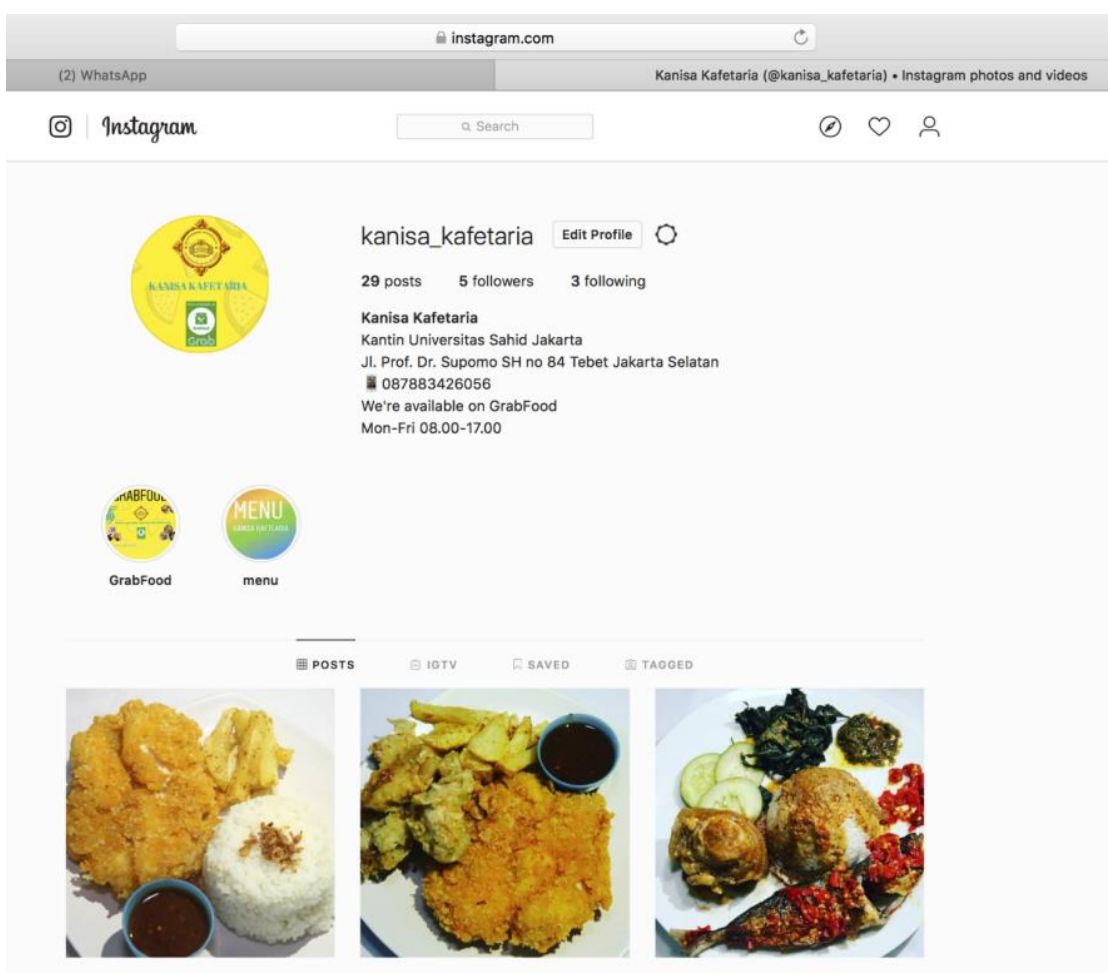

Gambar 3. Tampilan Akun KANISA Kafetaria dalam Aplikasi Instagram

4. Pendampingan dalam Mendaftarkan Produk dalam Aplikasi Online

Kegiatan ini bertujuan untuk membantu pelaku usaha jasa boga di kantin Universitas Sahid dalam mendaftarkan produk yang dijual ke dalam satu akun online. Saat ini Kanisa Kafetaria telah terdaftar di GrabFood (Gambar 4). Tim pengusul juga mencoba mendaftarkannya ke GoFood, namun karena terkendala akta Koperasi, sehingga belum disetujui oleh pihak GoFood. 


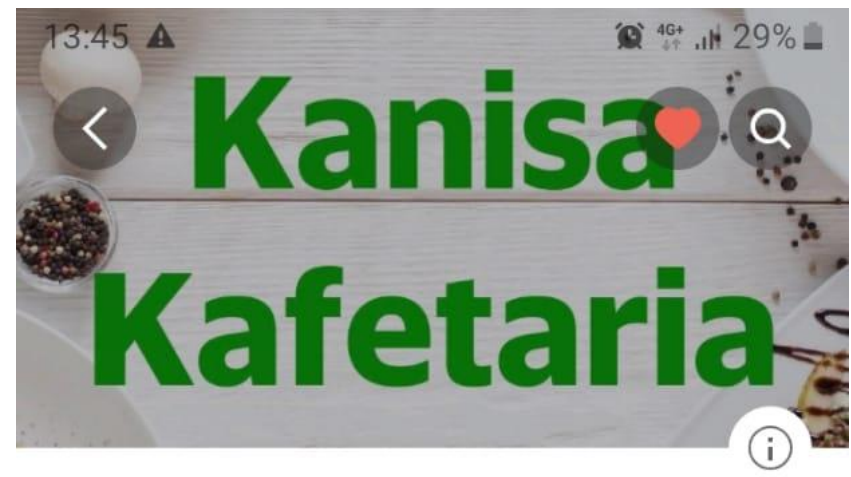

Preferred Merchants

\title{
Kanisa Kafetaria - Menteng Dalam
}

\author{
Rice \\ ○ $3.0 \mathrm{~km}$ ॠ $\mathrm{Rp} 6.000$
}

\section{Seblak}

Seblak Original

Seblak Sayap

Seblak Ceker

Seblak Bakso

Seblak Campur
22.500

22.500

22.500

22.500

22.500

\section{Gambar 4. Tampilan akun KANISA Kafetaria dalam Aplikasi GrabFood}

Selain dibuatkan akun GrabFood, pengusul kegiatan juga membuatkan desain banner dan neon box sebagai salah satu cara agar pengunjung sadar bahwa menu-menu di kantin Universitas Sahid Jakarta sudah dapat dibeli melalui GrabFood. Banner tersebut dipasang di gerbang masuk Universitas Sahid Jakarta dan di pintu kantin (Gambar 5, 6, dan 7). 


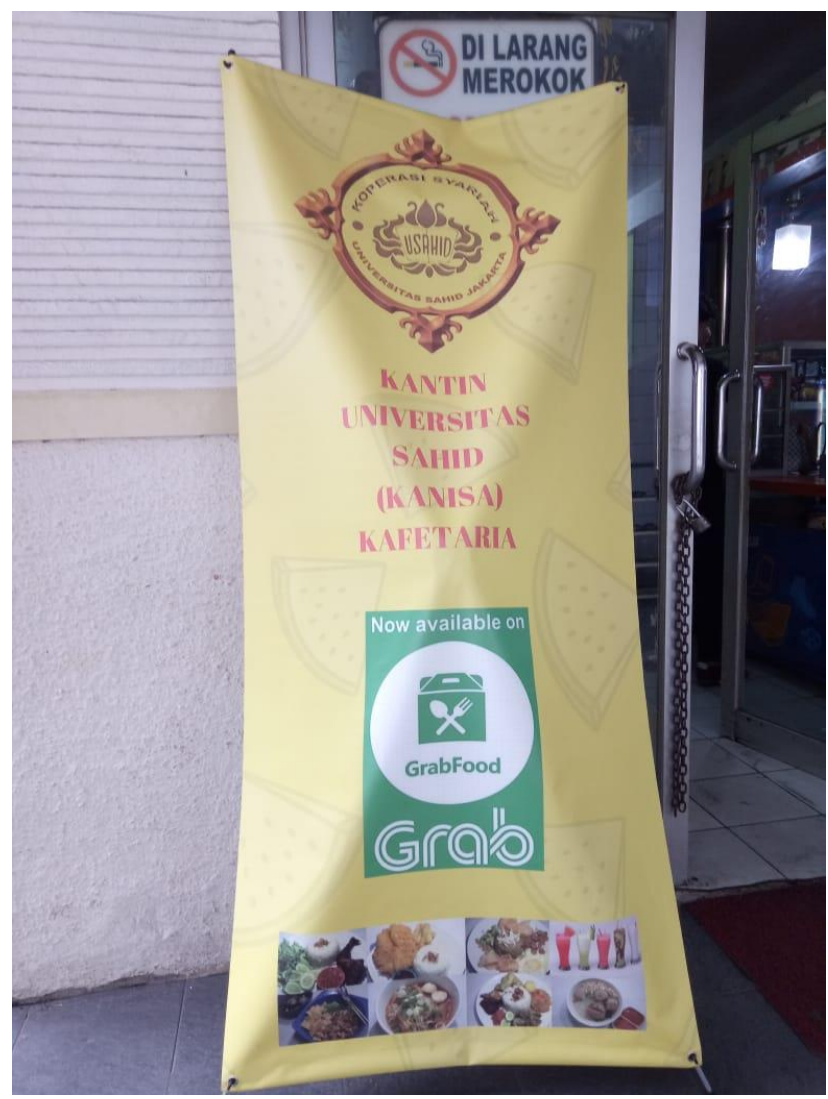

Gambar 5. Standing Banner KANISA Kafetaria

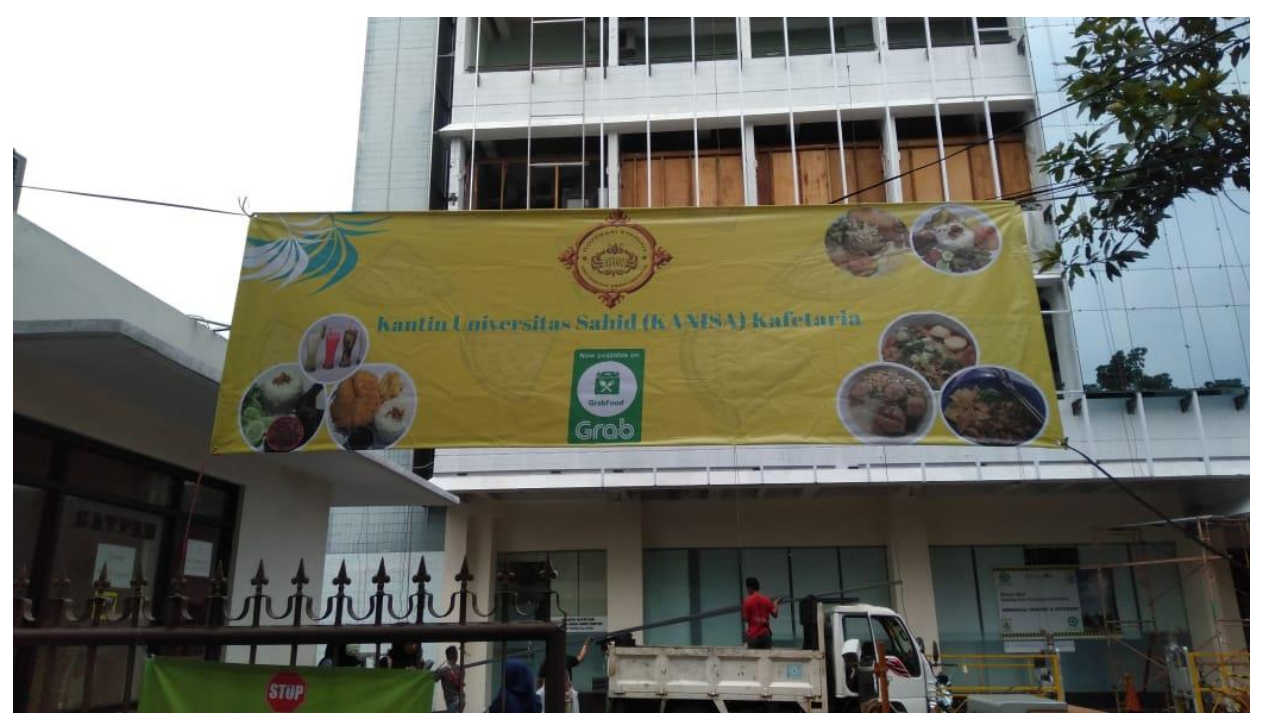

Gambar 6. Banner KANISA Kafetaria di Gerbang Masuk Universitas Sahid Jakarta 


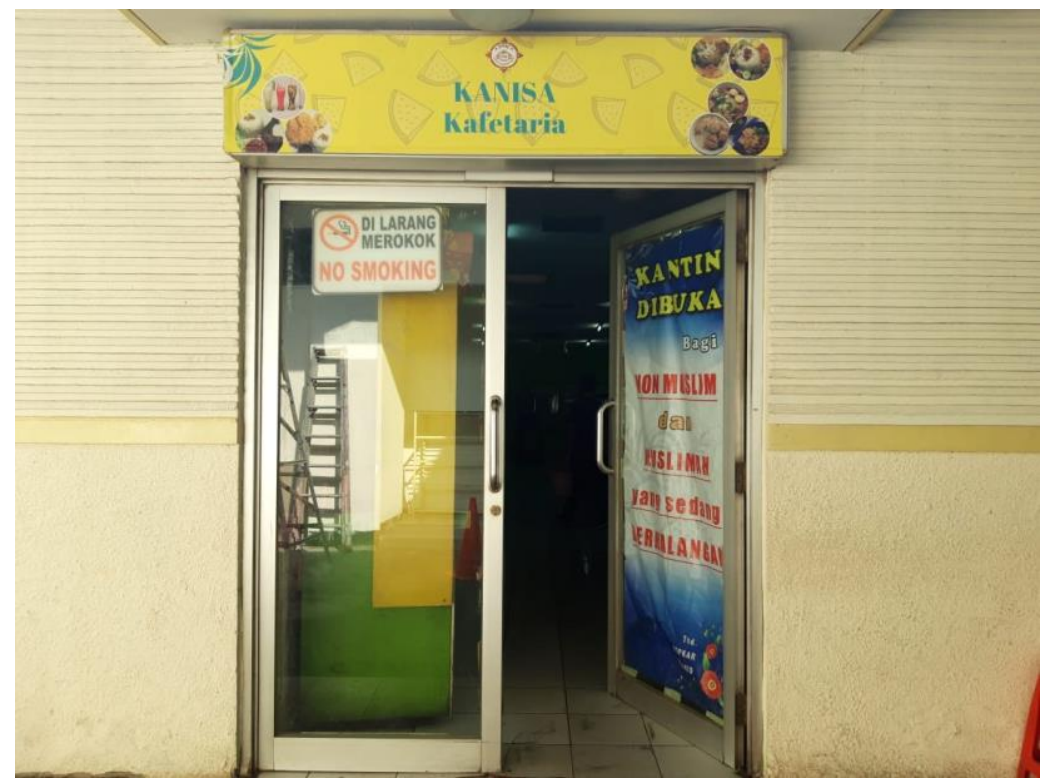

Gambar 7. Neon Box KANISA Kafetaria di Pintu Kantin

5. Pelatihan manajemen tata kelola usaha

Kegiatan ini bertujuan untuk meningkatkan kemampuan mitra dalam mengatur tata kelola usaha jasa boga.

\section{KESIMPULAN}

Mitra pada kegiatan pengabdian masyarakat ini adalah para pelaku usaha jasa boga di kantin Universitas Sahid Jakarta yang dinaungi oleh Koperasi Karyawan Universitas Sahid Jakarta. Tujuan dari kegiatan ini adalah untuk meningkatkan kapasitas usaha Kantin Universitas Sahid Jakarta. Adapun kegiatan ini terdiri dari beberapa tahap yaitu: pemetaan masalah, pelatihan higiene dan sanitasi usaha jasa boga serta pendampingan dalam memilih kemasan dan label untuk penjualan online, pendampingan promosi produk secara online, pendampingan dalam mendaftarkan produk dalam aplikasi online (GrabFood), dan pelatihan manajemen tata kelola usaha.

\section{UCAPAN TERIMA KASIH}

Terima kasih kepada Universitas Sahid Jakarta yang telah membiayai penelitian ini melalui Hibah Internal Pengabdian Masyarakat tahun 2018-2019. 


\section{DAFTAR PUSTAKA}

Eriksen K, Hemmingsen C. ONLINE MARKETING: NEW MODELS OF ADVERTISING? Internet. [diunduh: 7 Maret 2018]. Tersedia pada: http://projekter.aau.dk/projekter/files/16056831/081103_speciale.pdf

Vijakumaro GP, Julia, Lazuardhy MA, Ariasty SZ, Sona SH. 2017. LAPORAN PRAKTIKUM SANITASI DAN KEAMANAN PANGAN UJI KOLIFORM. Universitas Sahid Jakarta: Jakarta.

Onyeneho SN, Hedberg CW. AN ASSESSMENT OF FOOD SAFETY NEEDS OF RESTAURANTS IN OWERRI, IMO STATE, NIGERIA. Int. J. Environ. Res. Public Health 2013. (Vol. 10, pp. 3296-3309).

Azni IN, Giyatmi G, Amelia JR. STUDY OF CUSTOMER SATISFACTION AT CANTEEN OF SAHID UNIVERSITY-JAKARTA. InICCD 2019 Nov 28 (Vol. 2, No. 1, pp. 627-631). 